\title{
Erratum: International patent law-boon or bane of biotech?
}

\section{Paroma Basu}

Nat. Biotechnol. 23, 13-15 (2005)

On page 13, column 3, paragraph 4, line 16, The following, "the country's pharmaceutical exports were worth around $\$ 1.27$ billion in 2004 with generics accounting for 6\%" should have read "the country's total pharmaceutical output was worth around \$1.27 billion in 2004 with exports accounting for $6 \%$."

\section{Erratum: Poorer nations turn to publicly developed GM crops}

Joel I Cohen

Nat. Biotechnol. 23, 27-33 (2005)

In Table 1, page 28, the number of transformation events for South Africa should have been 28 not 20, and the number of events for Indonesia should have been 24 not 14. Also on page 28, column 1, line 18, the sentence "Some countries are working on five or fewer crops, whereas others, such as China and South Africa, are working on 15 or more." should have read "Some countries are working on five or fewer crops, whereas others, such as Indonesia and South Africa, are working on 13 or more." The authors have added the following sentence to end the paragraph, "Of all events, seven are in the commercial-release stage (see Fig. 4)." On page 31, column 2, bullet 2, line 3, "Eighty-four" should have read "Eighty-two." 